\title{
Underdiagnosis of Asthma in Syrian Shelters in Conflict Zones-Highlighting the Need for a Healthcare Training Program
}

\author{
Yousser Mohammad ${ }^{1,2}$
}

1. Syrian Private University, Damascus, Syria; 2. Tishreen University, National Center for Research for Chronic Respiratory Diseases (Collaborating with EMRO-WHO), Latakia, Syria

DOI: https://doi.org/10.17925/USRPD.2018.13.1.23

U nderdiagnosis of asthma is an important public health issue, particularly in conflict zones where populations are moved into crowded shelters. A survey of people living in Syrian shelters found a high prevalence of undiagnosed asthma. This is likely due to intense exposure of cooking fumes and tobacco smoke, as well as post-traumatic stress disorder. There is a need for chronic respiratory disease care in these settings.

\section{Keywords}

Asthma, chronic respiratory disease care, underdiagnosis

Disclosure: Yousser Mohammad has no conflicts of interest to disclose in relation to this article.

Review Process: This article is a short opinion piece and has not been submitted to external peer reviewers. A member of the Editorial Board reviewed the article before publication.

Acknowledgment: Youcef Latifeh, Syrian Private University and Damascus University, and Rafea Shaaban, Al-Andalus University for Medical Sciences, Syria, provided assistance in the design and statistics of the survey described in this article.

Authorship: The named author meets the International Committee of Medical Journal Editors (ICMJE) criteria for authorship of this manuscript, takes responsibility for the integrity of the work as a whole, and has given final approval for the version to be published.

open Access: This article is published under the Creative commons Attribution Non-commercial License, which permits any non-commercial use, distribution, adaptation, and reproduction provided the original author and source are given appropriate credit. (c) The Author 2018.

Received: July 27, 2018

Published Online: September 17, 2018 Citation: US Respiratory \& Pulmonary Diseases. 2018;3(1):23-4

Corresponding Author: Yousser Mohammad. Department of Internal Medicine, Tishreen University, Latakia, Syria. E: ccollaborating@gmail.com

Support: No funding was received in the publication of this article.
Underdiagnosis of asthma is an important issue for public health and also at individual level for asthma patients. The 2017 Global Initiative for Asthma used epidemiological surveys to compare the prevalence of asthma symptoms to doctor-diagnosed asthma in low and middle-income countries, revealing that $50 \%$ of asthma cases were underdiagnosed, especially in primary care facilities. ${ }^{1}$ Lack of medical knowledge of physicians in primary care plays an important role, as well as scarcity of spirometry. ${ }^{1}$ Even peak flow meter devices can be unavailable in some low and middle-income countries. ${ }^{2}$

Conflict and war could be responsible for augmenting the number of new onset asthma cases, with stress and new environmental triggers as possible contributing factors. Underdiagnosis of asthma could be exaggerated when the population is displaced from their homes and relocated to crowded shelters. ${ }^{3,4}$ In these conditions, medical care, such as that provided by World Health Organisation (WHO) programs, is emergency-oriented. ${ }^{5}$

While caring for patients in outpatient clinics at public hospitals, we were concerned to see how the conflict had resulted in new chemical triggers, high stress, and lack of adherence to inhaled corticosteroids in diagnosed asthma. We were also surprised by the number of underdiagnosed patients with new onset asthma arriving from conflict zones. This led us to investigate the rate of asthma symptoms in populations most directly affected by the armed conflict, and use spirometry to confirm it, where possible. ${ }^{3,4}$

Among the 1.6 million Syrians internally displaced, we decided that shelters were a good setting to investigate and survey those suffering from asthma-like symptoms, but not diagnosed as having asthma. ${ }^{3}$ Both the International Study of Asthma and Allergies in Childhood (ISAAC) worldwide epidemiologic survey, ${ }^{6}$ and the European Respiratory Health survey $(E R H S)^{7}$ were based on questionnaires to determine the prevalence of asthma. For ISAAC, when they compared current wheeze (wheezing in the last 12 months; considered as an indicator of current asthma), to hyper-responsiveness, a positive correlation was only found in half of the cases, and they concluded that $50 \%$ of cases were trivial wheeze. ${ }^{8}$

Asthma has been investigated among military personnel in Iraq and Afghanistan. Surveys showed that they experience a higher incidence of asthma onset compared with military personnel serving in their home land. The majority of war-based medical studies are conducted in military populations; however, we surveyed civil populations. ${ }^{3,4}$ 
The most reliable question in ERHS is related to waking at night with asthma symptoms. ${ }^{8}$ In Herjalleh Shelter, Rural Damascus, as part of our survey for asthma, the question about waking at night with asthma symptoms was administered to a sample of 204 out of 900 dwellers (5 years and older) with undiagnosed asthma; we were surprised to see that 44\% (91) responded yes to this question. ${ }^{3,4}$ When we performed spirometry, we were surprised to see forced expiratory volume in one second $\left(\mathrm{FEV}_{1}\right)<80 \%$ in $45 \%$ of positive respondents, and reversibility test confirming asthma diagnosis in all but five. These five could be undiagnosed chronic obstructive pulmonary disease (COPD) or asthma, or COPD overlap. Allergic rhinitis was noted in $57 \%$. ${ }^{3,4}$ If we compare the $44 \%$ in our study, to $5.2 \%$ current wheezers in ISAAC for Syria, or to $15 \%$ of Herjalleh dwellers staying at their homes, responding yes to waking at night by asthma symptoms, we understand that sheltered people have a higher prevalence of underdiagnosed asthma.

The reason for this should be investigated in more depth. In shelters, whole families will live in one room leading to higher exposure of cooking fumes and tobacco smoke as compared to their homes before displacement. This leads to intense exposure to small particles $\leq 2.5 \mu \mathrm{g}$. Additionally, the incidence of post-traumatic stress disorder is higher. This is important as it has been recognized that psychiatric disorders play a role in asthma onset, as stress deregulates the immune system. ${ }^{9,10}$
When we reviewed the care provided for shelter dwellers, we were informed that they were visited by general practitioners (GPS) in mobile clinics from the Red Cross, and have access to a primary care center run by the Ministry of Health $(\mathrm{MOH})$ near the shelter, and when needed, they are referred to university hospitals. However, there are no guidelines, algorithms, or programs for chronic respiratory disease (CRD) care provided by GPS in mobile clinics or health centers.

We conclude that asthma and other CRD daily care in shelters should be included in ongoing $\mathrm{MOH}-\mathrm{WHO}$ training programs at a national level.,.,4 Medical knowledge is an issue, and lack thereof is responsible for low quality of care. ${ }^{1,10}$ Academic participation in a multisectoral approach is the key. ${ }^{11}$ In this case they could supervise the development of algorithms, requiring the availability of essential medications (inhalers) and equipment (for peak expiratory flow) in health centers and mobile clinics for these CRDs, and for training GPS in mobile clinics and primary care centers on how to use inhalers, measure peak flow, and refer to spirometry centers.

The WHO Regional Office for the Eastern Mediterranean has integrated CRD into the emergency kit and produced a road map to help countries to achieve universal health coverage. Pollution and CRD are included; 5 this may help the WHO Action Plan 2013-2020 to be implemented. ${ }^{12} \square$
1. Global Initiative for Asthma. 2017 GINA Report, Global Strategy for Asthma Management and Prevention. Available at: https://ginasthma.org/wp-content/uploads/2016/01/wms-GINA2017-main-report-tracked-changes-for-archive.pdf (accessed July 1, 2018)

2. World Health Organization, Geneva. Prevention and Contro of Noncommunicable Diseases: Guidelines for primary health care in low resource settings. 2012. Available at: www.who.int/nmh/publications/phc2012/en/index.html (accessed July 1, 2018)

3. Mohammad Y, Rafea S, Latifeh Y, et al. Uncontrolled and under-diagnosed asthma in a Damascus shelter during the Syrian Crisis. J Thorc Dis. 2017:9:3415-24.

4. Boulet LP. War-time: Lessons from Syria. J Thorac Dis. 2017:9:3412-14.

5. World Health Organization, EMRO. The work of WHO in the
Eastern Mediterranean Region: annual report of the Regiona Director 1 January-31 December 2016. Available at: www.emro. who.int/annual-report/2016/index.html (accessed July 1, 2018).

6. Lai CKW, Beasley R, Crane J, et al. Global variation in the prevalence and severity of asthma symptoms: phase three of the International Study of Asthma and Allergies in Childhood (ISAAC). Thorax. 2009:64:476-83.

7. de Marco R, Zanolin ME, Accordini S, et al. A new questionnair for the repeat of the first stage of the European Community Respiratory Health Survey: a pilot study. Eur Respir J. 1999;14:1044-8.

8. Masoli M, Fabian D, Holt S, Beasley R. The global burden of asthma: executive summary of the GINA Dissemination Committee report. Allergy. 2004:59:469-78.

9. Jergovic M, Bendelja K, Vidovic A, et al. Patients with posttraumatic stress disorder exhibit an altered phenotype of regulatory T cells. Allergy Asthma Clin Immunol. 2014;10:43.

10. Phillips MJ, Smith EA, Mosquin PL, et al. Sri Lanka pilot study to examine respiratory health effects and personal PM2.5 exposures from cooking indoors. Int J Environ Res Public Health. 2016;13. pii: E791.

11. El-Jardali, Ataya N, Fadlallah R. Health Research Policy and Systems. Changing roles of universities in the era of SDGs: rising up to the global challenge through institutionalising partnerships with governments and communities. Health Res Policy Syst. 2018;16:38

12. World Health Organization. Global action plan for the prevention and control of noncommunicable diseases 2013-2020. Available at: www.who.int/nmh/events/ncd_action_plan/en/ (accessed July 1, 2018) 